\title{
Auto-regras como variáveis facilitadoras na emissão de comportamentos autocontrolados: o exemplo do comportamento alimentar
}

\author{
Adriana Alcântara dos Reis \\ Eveny da Rocha Teixeira \\ Carla Cristina Paiva Paracampo \\ Universidade Federal do Pará
}

\begin{abstract}
RESUMO
O presente trabalho se propõe a discutir e analisar o papel facilitador das auto-regras na emissão de desempenhos autocontrolados. Auto-regras podem tornar o desempenho insensível às contingências às quais o indivíduo está exposto e facilitar o desempenho do indivíduo em situações semelhantes àquela na qual já havia sido formulada uma auto-regra anteriormente. A partir do conhecimento das variáveis das quais seu comportamento é função, o indivíduo pode manipular as contingências relacionadas ao próprio comportamento alterando a probabilidade de sua emissão futura. A noção de autocontrole pode enfatizar dois aspectos: 1) o conflito entre as conseqüências positivas e negativas de uma resposta; e 2) a lacuna temporal entre a resposta e sua consequiência e a magnitude dos reforçadores/aversivos tanto a curto como a longo prazo. Uma vez que uma resposta autocontrolada foi emitida com sucesso, uma situação semelhante no futuro pode evocar a descrição da contingência passada, favorecendo a generalização do autocontrole. Foram utilizados exemplos relacionados ao comportamento alimentar para ilustrar possibilidades de intervenção clínica baseadas nas propostas de autocontrole formuladas por Skinner e por Rachlin. A terapia analítico-comportamental pode dar uma ênfase maior às auto-regras, a despeito de dificuldades teórico-metodológicas para identificar o seu papel em comportamentos de autocontrole.
\end{abstract}

Palavras-chave: autocontrole; auto-regras; comportamento alimentar.

\section{ABSTRACT \\ Self-rules as facilitating variables on the emission of self-controled behaviors: the example of feeding behavior}

\begin{abstract}
The present paper aims to discuss and analyze the facilitating role of self-rules in the emission of selfcontrolled behaviors. Self-rules can make the performance insensitive to contingencies to which the individual is exposed and can facilitate the performance of the individual in situations that are similar to the one in which a self-rule had been formulated previously. From the knowledge of the variables of which a behavior is functional, the individual can manipulate the contingencies related to his own behavior modifying the probability of future emission. The self-control definition can emphasize two aspects: 1) the conflict between positive and negative consequences of a response; and 2) the temporal gap between the response and its consequence and the magnitude of reinforcers/aversives both in short and long term contingencies. Once a self-controlled response was emitted successfully, a similar situation in the future can evoke the description of the past contingency, favoring the self-control generalization. Examples related to the feeding behavior were used to illustrate possibilities of clinical intervention based upon the self-control proposals formulated by Skinner and Rachlin. The behavioranalysis therapy can give a greater emphasis to self-rules, despite of the theoretical-methodological difficulties to identify its role in self-controlled behaviors.
\end{abstract}

Keywords: self-control; self-rules; feeding behavior.

A análise do comportamento não pode desconsiderar a relevância do aspecto verbal no estudo do comportamento humano, tendo em vista que grande parte do repertório comportamental é governado por regras. $\mathrm{Na}$ interação com membros da comunidade verbal o indivíduo aprende a descrever para si mesmo as contingências às quais está sendo exposto; esta descrição pode vir a exercer controle parcial sobre os comportamentos subseqüentes, tornando-se assim, um elo na cadeia comportamental que deve ser investigado no escopo da análise do comportamento.

Descrições verbais também estão envolvidas no autocontrole do comportamento, o qual pode ser definido como um tipo de manipulação de variáveis que tem como objetivo aumentar ou diminuir a probabilidade da emissão de uma resposta futura. Quando um indivíduo aprende a manipular variáveis, no sentido de tornar mais ou menos provável a emissão de uma resposta futura, pode a partir daí, derivar regras que 
facilitam a emissão de respostas autocontroladas em situações semelhantes.

Regras podem então ser definidas como estímulos verbais especificadores de contingências que podem funcionar como estímulos discriminativos, estímulos alteradores de função ou operações estabelecedoras (Albuquerque, 2001). O comportamento governado por regras é antecedido por um estímulo verbal que descreve as contingências de reforço; este estímulo tem função discriminativa quando está presente no ambiente imediato e torna-se um estímulo alterador de função quando há uma separação temporal entre o enunciado da regra e o surgimento do estímulo descrito pela regra e a subsequiente emissão do comportamento. Uma regra com a função de operação estabelecedora é um evento que altera a efetividade de uma conseqüência e evoca o comportamento que produz esta conseqüência (Albuquerque, 2001).

Auto-regras podem ser definidas como descrições de contingências enunciadas pelo próprio indivíduo, formuladas a partir de sua exposição às contingências de reforço, exercendo assim controle sobre a resposta subseqüente ou, de outro modo, uma regra enunciada por um falante confiável pode passar a exercer a função de uma auto-regra para o indivíduo. Deve-se considerar, contudo, que auto-regras, tanto as formuladas pelo próprio indivíduo quanto as enunciadas por outro falante, podem não descrever fidedignamente as contingências em vigor.

O autoconhecimento é condição para a formulação de auto-regras acuradas. A comunidade verbal estimula tatos fidedignos quando questiona o indivíduo sobre o que fez, o que está fazendo e o que vai fazer e sobre as situações em que este comportamento foi emitido no passado. Assim, pode-se afirmar que o autoconhecimento é função da interação do indivíduo com o ambiente social. Para que um indivíduo descreva verbalmente os comportamentos que pretende emitir no futuro, deve conhecer as variáveis das quais seu comportamento foi função no passado. Se este conhecimento das contingências é falho, o indivíduo pode ficar sob controle de auto-regras imprecisas. Isto ocorre por conta de restrições de acesso da comunidade aos eventos passados/privados, o que dificulta a modelagem do repertório descritivo (Skinner, 1974).

$\mathrm{O}$ autoconhecimento é compreendido como um pré-requisito para o comportamento de autocontrole. Através do autoconhecimento, o indivíduo aprende tanto a observar e descrever seu próprio comportamento, como a relacioná-lo com variáveis ambientais, passando a derivar (auto-) regras do tipo "se...então" que podem ser usadas em ocasiões futuras. Logo, o autoconhecimento pode levar à formulação de (auto-) regras que favoreçam a emissão de comportamentos autocontrolados.
As auto-regras exercem papel facilitador na determinação do comportamento autocontrolado de pelo menos duas maneiras: tornando o desempenho insensível às contingências às quais o indivíduo está exposto, isto é, mantendo a resposta sob controle prevalente das variáveis descritas pela regra, ou ainda, tornando vívida a contingência em vigor, ao enfatizar a relação do comportamento com suas prováveis conseqüências. Este papel facilitador das auto-regras na emissão de um desempenho futuro é um importante elo no paradigma do autocontrole.

A noção de autocontrole pode enfatizar dois aspectos: 1) o conflito entre as consequiências positivas e negativas de uma resposta, como na proposta de Skinner (1953); e 2) a lacuna temporal entre a resposta e sua conseqüência e a magnitude dos reforçadores/aversivos tanto a curto como a longo prazo, na perspectiva de Rachlin (1974, 1991). Embora a temporalidade e a magnitude sejam diferenciais relevantes entre os dois paradigmas, as duas propostas podem ser consideradas complementares na medida em que ambas referem-se ao autocontrole como um tipo de manipulação de variáveis com a função de tornar mais ou menos provável a emissão de uma resposta subseqüente.

De acordo com Skinner (1953), a necessidade do autocontrole surge quando uma mesma resposta gera conseqüências tanto positivas quanto negativas, instaurando-se assim um conflito. Tal conflito freqüentemente envolve conseqüências para o indivíduo que contrastam com o interesse do grupo.

Um exemplo de conflito ao qual Skinner de refere pode ser extraído de uma situação na qual se opta por ir à piscina ao invés de realizar um trabalho escolar na casa de um amigo: ir à piscina produz consequiências positivas, mas também consequiências negativas como punição social por parte do amigo. A manipulação das variáveis que altera a probabilidade de emissão de uma dada resposta é denominada resposta controladora. Na situação em questão, uma resposta controladora seria a emissão de auto-verbalizações, com função de estímulo, que descrevessem a contingência em vigor ("se eu for à piscina, o meu amigo ficará chateado comigo e eu não terei nota no trabalho"). A resposta controlada seria a resposta de ir à piscina, suprimida a partir dessa manipulação de variável.

Reconhecendo a dificuldade para emissão de comportamentos autocontrolados, Skinner (1953) enfatiza a importância das contingências sociais tanto para a instalação como para a manutenção do repertório de autocontrole. Dessa forma, o próprio autor destaca como fonte última de controle do comportamento as variáveis no ambiente social. Partindo da análise do autocontrole proposta por Skinner, Nico (2001) afirma que o indivíduo está exposto a sanções sociais e éticas que o impelem a emitir comportamentos que beneficiam 
o grupo em detrimento daqueles que beneficiam o indivíduo.

A proposta de Rachlin $(1974,1991)$ destaca o papel das contingências futuras na determinação do comportamento autocontrolado. Recompensas de menor magnitude disponíveis no ambiente freqüentemente devem ser ignoradas para que uma recompensa maior possa ser obtida, como quando deixamos de comprar coisas supérfluas agora para adquirir um bem mais precioso no futuro ou deixamos de comer doces e frituras agora para perder peso em alguns meses. De modo contrário, também se pode evitar grandes aversivos no futuro através de pequenos aversivos no presente, como deixar de fumar para se evitar as doenças apregoadas nas embalagens de cigarro ou usar fio dental diariamente, a despeito do incômodo que possa causar, para evitar cáries.

Indivíduos que esperam por um longo tempo têm que se comportar na presença da recompensa como se ela não estivesse lá; logo, algo pode ser feito para prevenir a disponibilidade subseqüente das recompensas menores. Isto é o que Rachlin $(1974,1991)$ denomina resposta de compromisso: emissão de comportamentos alternativos, que possam competir com o comportamento que deve ser evitado (como ligar para a melhor amiga em vez de ligar para o ex-namorado), ou ainda, emissão de respostas que reduzam o valor reforçador das consequiências produzidas pelo comportamento inadequado (por exemplo, come-se salada antes do prato principal para reduzir a quantidade de macarronada ingerida depois).

A resposta de compromisso pode ser antecedida ou não por uma promessa - um estabelecimento de metas que pode ser emitido privada ou publicamente. Quando a promessa é publicizada, garante-se um certo controle social sobre a resposta indesejada (ao contarmos aos nossos amigos sobre nossa tentativa de fazer dieta, damos a eles direito de monitorar nossos esforços). Penalidades podem ser estabelecidas para o seu não-seguimento. $\mathrm{O}$ efeito da resposta de compromisso é a redução das escolhas disponíveis, forçando o indivíduo a emitir a resposta que levará ao reforçador a longo prazo (Rachlin, 1974, 1991).

A manutenção dos comportamentos cujas conseqüências são improváveis ou remotas depende, em certa medida, de mediação social, visto que estas estão a muito longo prazo para exercer um controle eficaz sobre o comportamento. As conseqüências com as quais o indivíduo de fato mantém contato são aquelas providas pela comunidade verbal, que exerce o papel de monitorização do comportamento, aumentando assim a sua probabilidade de emissão. Grande parte das auto-regras envolvidas na emissão do comportamento autocontrolado enfatiza tais conseqüências sociais.
A noção de autocontrole proposta por Rachlin (1974, 1991), de acordo com a qual reforçadores de longo prazo estão em competição com reforçadores imediatos de menor magnitude, pode ser descrita como um tipo de contingência de ação indireta. Segundo Malott (1989), a formulação de regras é uma condição facilitadora para o cumprimento de tarefas cujas consequiências são de longo prazo, improváveis ou muito pequenas (comportamentos mantidos por contingências indiretas). Regras possibilitam o conhecimento da contingência de ação indireta, tornando mais provável a emissão de comportamentos que geram reforçadores de maior magnitude a longo prazo e a insensibilidade a reforçadores imediatos.

Dentre as condições necessárias para o controle por contingências indiretas, Mallot (1989) cita a autoavaliação - que possibilita ao indivíduo determinar quando o próprio comportamento corresponde à regra que descreve contingências de longo prazo, para que recompensas e punições sejam liberadas; o autoreforçamento - definido como a administração de conseqüências pelo próprio indivíduo, contingente ao seguimento desta regra (a eficácia destas consequiências é determinada pela história ambiental); o estabelecimento de metas públicas - que funcionam como um estímulo discriminativo para o controle social (reforçamento de comportamentos compatíveis com a regra e punição de comportamentos que a contradizem). Todos esses fatores estão envolvidos com a noção de autocontrole e autogerenciamento.

O autocontrole também é necessário quando as contingências são diretas, caso dois tipos de conseqüências estejam em competição - reforçadoras e aversivas (Skinner, 1953). Nas ocasiões em que o comportamento autocontrolado não ocorreria naturalmente, dado o apelo do outro conjunto de contingências, faz-se necessária a formulação de (auto-) regras.

Zettle e Hayes (1982) denominam de auto-ply regras enunciadas pelo próprio indivíduo que descrevem conseqüências sociais para seu (não) seguimento, e auto-augmental regras que alteram o valor reforçador dos eventos por elas descritos. Exemplificando, o comportamento correspondente à verbalização "vou para casa, pois se eu permanecer mais tempo aqui no bar, vou ter problemas com minha esposa" pode ser denominado de auto-pliance, enquanto que o comportamento que segue a verbalização "Quando encontrar meu ex-namorado hoje à noite preciso me lembrar o quanto ele me magoou e dar o troco" pode ser identificado como auto-augmenting, e ambos ilustram como auto-regras podem facilitar a emissão de respostas autocontroladas.

Uma vez que uma resposta autocontrolada foi emitida com sucesso, uma situação semelhante no futuro pode evocar a descrição da contingência passa- 
da, favorecendo a ampliação do repertório de autocontrole. A auto-regra generalizada para esta nova situação que demanda a emissão de um desempenho autocontrolado mantém sua função facilitadora, posto que torna o desempenho insensível aos reforçadores presentes no ambiente imediato e clarifica a contingência em vigor. Por exemplo, ao aprender que a restrição de estímulos distrativos (como evitar comprar gibis) aumenta a probabilidade da emissão de um comportamento de estudo, a mesma estratégia pode ser utilizada para aumentar a probabilidade de fazer dieta, ao reduzir a disponibilidade de guloseimas (como evitar comprar biscoitos doces). Estas situações nas quais auto-regras podem funcionar como um elo comportamental na cadeia do autocontrole serão esquematizadas nos quadros que se seguem:

\begin{tabular}{|c|l|l|}
\hline R1 (fumar) & $\begin{array}{l}\text { Conseqüência direta } \\
\text { Sensações fisiológicas agradáveis e elimi- } \\
\text { nação da condição de privação }\end{array}$ & $\begin{array}{l}\text { Consequiência indireta } \\
\text { Danos à saúde (risco de câncer, } \\
\text { impotência sexual, problemas } \\
\text { cardíacos etc.) }\end{array}$ \\
\hline
\end{tabular}

\begin{tabular}{|c|c|c|}
\hline \multicolumn{2}{|c|}{$\begin{array}{l}\text { Auto-regra: "Não quero correr o risco de um enfarto. Vou cami- } \\
\text { nhar em vez de fumar". }\end{array}$} & \\
\hline R2 (caminhar) & $\begin{array}{l}\quad \text { Consequiência direta } \\
\text { Evitação / privação do cigarro } \\
\text { Contato com novas pessoas; bem-estar }\end{array}$ & $\begin{array}{l}\text { Consequiência indireta } \\
\text { Redução de danos à saúde (risco de } \\
\text { câncer, impotência sexual, problemas } \\
\text { cardíacos etc.) }\end{array}$ \\
\hline
\end{tabular}

Figura 1: Contingências de ação indireta

\begin{tabular}{|c|c|c|}
\hline R1 (ir à piscina) & $\begin{array}{c}\text { Consequiência positiva } \\
\text { Relaxar, pegar sol }\end{array}$ & $\begin{array}{c}\text { Consequêencia aversiva } \\
\text { Deixar de estudar e ter nota no } \\
\text { trabalho; brigar com o amigo }\end{array}$ \\
\hline \begin{tabular}{|c|c|c|} 
Auto-regra: "Se eu for à piscina, o meu amigo ficará chateado comigo \\
e eu não terei nota no trabalho."
\end{tabular} & $\begin{array}{c}\text { Conseqüência positiva } \\
\text { Estudar e ter nota no trabalho; } \\
\text { encontrar o amigo }\end{array}$ & Deixar de relaxar, pegar sol aversiva \\
\hline R2 (estudar)
\end{tabular}

Figura 2: Contingências de ação direta

\begin{tabular}{|l|l|l|}
\hline & \multicolumn{1}{|c|}{ Conseqüência positiva } & \multicolumn{1}{c|}{ Consequiência aversiva } \\
\hline R1 (comprar gibis) & Ler gibis & Deixar de estudar e ter nota baixa \\
\hline R2 (estudar) & Aquisição de conhecimento; boa nota & Deixar de ler gibis \\
\hline
\end{tabular}

Auto-regra: "É melhor não comprar nada que me distraia do meu objetivo." 


\begin{tabular}{|l|l|l|}
\hline R2 (não comprar biscoito e fazer dieta) & $\begin{array}{c}\text { Conseqüência positiva } \\
\text { Perder peso }\end{array}$ & $\begin{array}{c}\text { Consequiência aversiva } \\
\text { Privação de doces }\end{array}$ \\
\hline
\end{tabular}

Figura 3: Generalização do autocontrole através de regras

\section{Implicações práticas da relação entre auto-regras e autocontrole}

Grande parte da demanda clínica está relacionada com a necessidade de aprender a emitir comportamentos autocontrolados. Este aprendizado pode ser estimulado através da modelagem de descrições verbais adequadas das contingências. Dado o comportamento humano fazer parte de cadeias comportamentais complexas, com grande extensão temporal entre uma resposta e a sua conseqüência efetiva, é de fundamental importância a elaboração de auto-regras que descrevam acuradamente as contingências em vigor. No contexto terapêutico analítico-comportamental, a elaboração e modificação de auto-regras é favorecida pelo fortalecimento do repertório de autoconhecimento.

Um exemplo que ilustra a necessidade do uso de estratégias de autocontrole são os repertórios comportamentais relacionados à saúde, por implicarem na disponibilidade de reforçadores imediatos que devem ser ignorados e na probabilidade de obtenção de benefícios em um tempo futuro, tais como, a evitação de substâncias psicoativas (nicotina, álcool etc.), a emissão de comportamentos de higiene (lavar as mãos, higiene bucal freqüente), a prática regular de atividades físicas, a adoção de hábitos alimentares saudáveis, dentre outros.

Quando uma pessoa com dislipidemia opta por ingerir alimentos de baixo teor calórico (pobres em açúcares e graxos) e ricos em fibras, perde alguns reforçadores imediatos como o paladar e o aroma de alimentos que compunham a dieta habitual e o reforçador social presente em churrascadas e festinhas. Em contrapartida, os reforçadores para o seguimento de uma dieta surgem muito a longo prazo (perda de peso, redução do colesterol) ou são apenas prováveis (diminuição do risco cardíaco).

A dificuldade em emitir desempenho autocontrolado pode estar relacionada com o fato dos indivíduos não disporem de pré-requisitos comportamentais como a auto-observação e o autoconhecimento, os quais podem ser aprendidos no contexto terapêutico.

O processo terapêutico analítico-comportamental, ao focar o comportamento alimentar inadequado, busca as variáveis das quais aquele comportamento é função. $\mathrm{O}$ terapeuta, além de identificar reforçadores imediatos que controlam o comportamento do indivíduo, deve ensinar o cliente a fazê-lo. O repertório de auto-observação deve ser instalado antes que se tente estabelecer diretamente um desempenho autocontrolado diante da comida, sob a pena de tornar o processo terapêutico tecnicista e de difícil generalização. $\mathrm{Na}$ fase seguinte, de automonitoramento, são comuns tarefas de registro que devem ser preenchidas em casa e analisadas em conjunto com o terapeuta.

Depois que o cliente está instrumentalizado a quantificar os alimentos que ingeriu e a sinalizar em que ocasiões os ingeriu com mais frequiência, torna-se apto a identificar as situações que demandam a emissão de autocontrole e quais as respostas controladoras mais adequadas para cada situação. $\mathrm{O}$ autogerenciamento exige que o indivíduo seja capaz de programar a liberação de conseqüências e, para tanto, basta que haja uma história ambiental que garanta este tipo de aprendizagem.

Quando o cliente passa a analisar funcionalmente seus comportamentos, emitindo respostas mais eficientes a longo prazo e ficando cada vez menos sob controle dos reforçadores imediatos disponíveis, pode daí derivar regras, que sinalizam novas ocasiões em que respostas autocontroladas devem ser emitidas e tornam mais vívidas a contingência que está em operação (Rachlin, 1974, 1991).

No contexto clínico, muitas queixas estão relacionadas com a necessidade de controle do comportamento alimentar. Considerando isto, o tópico a seguir utilizará exemplos relacionados ao comportamento alimentar para ilustrar possibilidades de intervenção clínica baseadas nas propostas de autocontrole formuladas por Skinner $(1953,1974)$ e por Rachlin $(1974,1991)$.

\section{Técnicas de autocontrole aplicadas ao comportamento alimentar}

Skinner (1953) sugere algumas técnicas de controle de comportamentos, nas quais possibilidades de controle por auto-regras serão exploradas de acordo com a proposta inicial do presente trabalho.

- Mudança de estímulos: nesta técnica, manipulam-se estímulos discriminativos ou eliciadores do comportamento a ser controlado. Exemplos são: retirar potes de doce da geladeira; esconder pacotes de biscoito no armário, em vez de deixá-los à mostra na 
prateleira. Auto-regra possível: "vou botar essas cocadas em um pote que não seja transparente, assim nem as vejo...".

- Privação e saciação: "uma pessoa (...) pode saciarse parcialmente com uma refeição ligeira antes de ir jantar para tornar a probabilidade de emissão do seu comportamento menos conspícua. Quando um convidado se prepara para ir a um coquetel oferecido por uma anfitriã insistente bebendo antes grande quantidade de água, usa auto-saciação como medida de controle." (Skinner, 1953, pp. 227-228). Auto-regra possível: "vou comer mais salada antes de me servir da macarronada".

- Manipulação de condições emocionais: indução de mudanças emocionais com propósito de controle (apresentação ou remoção de estímulos que adquirem o poder de evocar reações emocionais por causa dos eventos que ocorreram em conexão com eles). Exemplo: um indivíduo pode suprimir o comportamento de tomar refrigerante relembrando sua última reação alérgica causada por corantes. Auto-regra possível: "da última vez que tomei refrigerante fiquei com o rosto inchado por três dias...".

- Uso de estimulação aversiva: condicionamento de reações aversivas através de emparelhamento de estímulos ou criar estímulos verbais que tenham efeito sobre o indivíduo por causa das consequiências aversivas passadas. Exemplo: um indivíduo coloca a receita da nutricionista na porta da geladeira, presa em ímãs de porquinhos. Auto-regra possível: "ou sigo esta dieta ou fico gorda como este porquinho!".

- Drogas: uso de drogas que estimulam o efeito de outras variáveis no autocontrole, que não possam ser facilmente alterados de outra maneira. Exemplo: na síndrome Prader-Willi, que afeta o hipotálamo (região do cérebro que regula a fome e a saciedade), o comportamento de comer deve ser controlado com ansiolítico. Auto-regra possível: "se não tomar o meu remédio agora, daqui a pouco vou sentir aquela urgência em comer!".

- Condicionamento operante: "Não é bem claro o lugar do condicionamento operante no autocontrole. (...) $\mathrm{O}$ auto-reforço do comportamento operante pressupõe que o indivíduo tenha o poder de obter reforço mas não o faz enquanto uma resposta particular não for emitida" (Skinner, 1953, pp. 230-231). Exemplo: uma pessoa estabelece que só assistirá televisão à noite se durante o dia seguir a dieta prescrita. Autoregra possível: "Se eu comer demais, fico sem minha novela!...”.

- Punição: um indivíduo pode administrar autoestimulação aversiva contingentemente a uma resposta. Exemplo: "o homem preocupado com a redução do peso pode apertar o cinto o máximo possível e continuar assim, apesar de forte efeito aversivo" (Skinner, 1953, p. 232). Auto-regra possível: "não deveria ter ido à churrascaria... Aquela gordura pode afetar meu coração. Que peso na consciência!".

- "Fazer alguma outra coisa": emissão de comportamento alternativo ou incompatível. Exemplo: um indivíduo vai à cozinha e bebe água em vez de comer. Auto-regra possível: "não, não vou comer essa torta de chocolate... melhor beber água”.

De maneira semelhante como foram utilizados os exemplos elaborados por Skinner (1953), também serão exploradas as técnicas de autocontrole apresentadas por Rachlin (1974, 1991).

- Autocontrole de "força bruta": quando a tentação é oferecida e simplesmente recusada. A causa direta de tal comportamento é a correlação de longo prazo entre o seu comportamento e suas conseqüências. Exemplo: o indivíduo passa pela porta da padaria sem entrar para comprar pão. Auto-regra possível: "Se eu comer pão, não conseguirei perder peso...".

- Auto-reforço: o indivíduo recompensa a si mesmo por ter emitido um comportamento. Esta recompensa adquire função de estímulo, na medida em que torna mais vívida a contingência de longo prazo. No processo de aprendizagem, o comportamento autocontrolado passa a ficar gradativamente sob controle de reforçadores externos. Exemplo: Uma pessoa pode estabelecer que a cada quilo perdido por seguir corretamente recomendações nutricionais irá presentear-se com uma peça de roupa nova. Como a cada quilo perdido o manequim da roupa diminuirá, comprar roupas cada vez menores pode adquirir valor reforçador. Esta pessoa pode comprar roupas mesmo sem ter perdido peso, mas serão roupas sempre do mesmo tamanho e assim, a relação entre o perder peso e suas conseqüências (como sentir-se bem em frente ao espelho, receber elogios) não estará sendo ressaltada. Auto-regra possível: "A cada quilo perdido, comprarei uma peça de roupa nova! Vou comer mais salada e menos arroz durante essa semana... Será que aquela calça $n^{\circ} 38$ vai caber se eu perder um quilo? A vendedora disse que ia guardar até sábado...".

- Compromisso: tem a função de reduzir as escolhas do indivíduo - compeli-lo a comportar-se de acordo com as contingências de longo prazo; é um contrato que especifica as consequiências que serão administradas em função do comportamento emitido. Uma resposta de compromisso tem a função tanto de prevenir a disponibilidade subseqüente da recompensa menor ou substancialmente reduzir o seu valor enquanto a recompensa maior ainda pode ser obtida. Promessas e resoluções são tipos de compromissos que dependem da história do indivíduo em seguir regras; elas não evitam a tentação, mas reduzem o seu valor reforçador. Exemplo: ao entrar no supermercado um indivíduo estabelece que todos os alimentos caló- 
ricos que colocar em seu carrinho serão doados aos carregadores de compras. Auto-regra possível: "Esse ano vou conseguir perder os cinco quilos que preciso... Vou tomar mais cuidado com o que ponho no meu carrinho de compras".

As técnicas sugeridas por Skinner (1953) e Rachlin (1974, 1991) ora apresentadas não se configuram como uma prescrição para a atuação em contexto terapêutico, posto que apenas foram utilizadas para ilustrar como auto-regras podem estar envolvidas no comportamento autocontrolado. $\mathrm{O}$ uso de técnicas de autocontrole só se justifica dentro de um contexto analítico-funcional no qual sejam identificadas as variáveis controladoras do comportamento foco de intervenção.

\section{CONSIDERAÇÕES FINAIS}

Sujeitos humanos não podem ser isolados de sua capacidade verbal. Desempenhos não-verbais são sempre acompanhados por auto-verbalizações - um produto colateral das contingências - mesmo que estas não exerçam nenhum papel causal sobre eles. A terapia analítico-comportamental pode dar uma ênfase maior às auto-regras, tendo em vista que são um importante elo na cadeia comportamental. A despeito de dificuldades teórico-metodológicas para identificar o papel das auto-regras em comportamentos de autocontrole, analistas do comportamento não devem, sob esta justificativa, se isentar de operar sobre elas.

A atuação de terapeutas analítico-comportamentais sobre auto-regras no contexto clínico ocorre, com mais frequiência, para identificar verbalizações que não descrevem adequadamente as variáveis controladoras do comportamento; contudo, este trabalho vem ressaltar que a manipulação de contingências pode resultar na elaboração de auto-regras que favorecem a emissão de comportamentos autocontrolados - dentre os quais destacamos os comportamentos pró-saúde - e que tais auto-regras devem ser valorizadas por seu papel facilitador na emissão de tais comportamentos.

\section{REFERÊNCIAS}

Albuquerque, L. C. (2001). Definição de regras. Em H. J. Guilhardi, M. B. B. P. Madi, P. P. Queiroz, P. P. \& M. C. Scoz (Orgs.), Sobre comportamento e cognição: expondo a variabilidade (pp. 132-140). Santo André: Esetec.

Malott, R. (1989). The achievement of evasive goals: Control by rules describing contingencies that are not direct acting. Em S. C. Hayes (Org.), Rule-governed behavior: cognition, contingencies, and instructional control (pp. 269-322). New York: Plenum Press.

Nico, Y. C. (2001). A contribuição de B. F. Skinner para o ensino do autocontrole como objetivo da educação. Dissertação de mestrado não publicada. Pontifícia Universidade Católica, São Paulo.

Rachlin, H. (1974). Self-control. Behaviorism, 2, 94-107.

Rachlin, H. (1991). Introduction to modern behaviorism. New York: Freeman.

Skinner, B. F. (1953). Science and human behavior. New York/London: Free Press/Collier MacMillan.

Skinner, B. F. (1974). About Behaviorism. New York: Alfred A. Knopf.

Zettle, R. D. \& Hayes, S. C. (1982). Rule-governed behavior: a potencial theorical framework for cognitive-behavioral therapy. Em P. C. Kendal (Org.), Advances in cognitive-behavioral research and therapy. Vol. 1 (pp. 76-118). London: Academic Press.

Enviado: 01/12/2004 Revisado: 22/03/2005 Aceito: 10/06/2005

\section{Sobre as autoras:}

Adriana Alcântara dos Reis: Psicóloga e Mestranda do Programa de Pós-Graduação em Teoria e Pesquisa do Comportamento da Universidade Federal do Pará. Endereço eletrônico: e-mail: aar@cpgp.ufpa.br.

Eveny da Rocha Teixeira: Psicóloga e Mestranda do Programa de Pós-Graduação em Teoria e Pesquisa do Comportamento da Universidade Federal do Pará.

Profa. Dra. Carla Cristina Paiva Paracampo - Docente do Programa de Pós-Graduação em Teoria e Pesquisa do Comportamento da Universidade Federal do Pará. 
